have given rise to more decided and graver symptoms from the beginning. The only probable explanation is, that the effusion took place very gradually, had room to extend itself, and coagulated slowly and imperfectly. Until the paralysis of the diaphragm, showing dangerous interference with the functions of the phrenic nerves, nearly every symptom might have been attributed to one or other of those obscure forms of hysteria so frequently met with in practice. Notting-hill-square, Notting-hill, June, 1869.

\section{A CASE OF ENCYSTED ABDOMINAL TUMOUR.} SPONTANEOUS RECOVERY.

By E. F. FUSSELL, M.B., M.R.C.P., PHYSICIAN TO THE BRIGHTON DISPENSARY.

Is a large number of abdominal tumours it is universally acknowledged that their true nature can only be determined by such precise tests as the knife of the surgeon, the successful efforts of nature to rid herself of that which is hurtful, or the evidence which a post-mortem reveals to the researches of the pathologist. The following case affords a remarkable example of the fact, that if these tumours be a stumbling-block to the ordinary physician, they are sometimes no less puzzling to those who have made them their especial study.

Mrs. $\mathbf{P} \longrightarrow$, aged forty-two, married, with two children, consulted me in the early part of 1868 for a swelling at the upper part of the right iliac fossa. It was painless, about the size of an orange, and presented in its general features much the aspect of an hydatid or ovarian tumour. Catamenia irregular. Nothing abnormal could be felt per vaginam. In the course of six months it gradually increased, without any active symptoms, until it became as large as a child's head; it was much less defined, and less globular, than it was at first; rather tense; not absolutely dull to percussion. No fluctuation, and no solid body, could be detected. Uterus not enlarged.

She consulted a physician at Weston-super-Mare; and on her return the tumour had increased in size, and began to cause her much uneasiness. She said she was about to go into the London Hospital to be operated upon. To this I demurred, and requested a consultation with an authority in town, who pronounced it a "ventral hernia ;" and she was directed to wear a graduated air compress. A few days afterwards a red spot appeared on the surface of the tumour, and in the course of a week she wrote-" The boil has broken, a quantity of yellowish-looking water has come away, and the swelling has vanished." To tactile examination there was only a fulness, and on her standing up but a slight bulging. From the minute opening I obtained a teaspoonful of thin sero-purulent fluid, which under the microscope exhibited some blood-and pus-corpuscles, but nothing else noteworthy. She subsequently saw a distinguished obstetrician in Edinburgh, who spoke of an injection, but afterwards determined to leave it alone. There was a slight oozing for several months. There is now a puckered cicatrix, and for a few inches in its neighbourhood the integuments feel thickened and hard. She has miscarried lately, but is at the present time (June, 1869) quite well.

What was the nature of this tumour? Besides the two diseases above-mentioned, it presented characters common to several others in its position, growth, dimensions, and phenomena discoverable prior to its bursting-e.g., psoas abscess, pelvic abscess, colloid cysts. Of the second of these a case is mentioned by $\mathrm{Dr}$. M'Clintock, in which the swelling must have equalled, if not exceeded, that which I describe. Cystic disease of the kidney sometimes forms a tumour in front of the intestines, entirely confounding the diagnosis; * and the urine may be normal if the diseased kidney has ceased to secrete, and if the other is healthy. Colloid cysts may contain fluid of the utmost diversity in thickness, and be mistaken for ovarian tumours. $f$ Dr. Crawford $\neq$ has pub* THR LANCET, March, 1865 .

†St. George’s Pathological Catalogue, $p, 511$.
$\ddagger$ Medieal Times and Gazette, March, 1867 . lished a case of spontaneous cure of an ovarian cyst by the discharge of its contents through the abdominal wall. But of all the outlets by which ovarian tumours sometimes empty themselres, the external abdominal issue is, according to most authors, less often followed by a cure than when they escape by other channels. I am not even now prepared to state accurately the precise origin of the formation of the cystic tumour that I have related. It may have been an ovarian crst which inflamed and suppurated, or a chronic abscess altogether confined to the abdominal parietes. Brighton, June, 1869.

\section{EFFECTS OF A PISTOL-SHOT FIRED CLOSE TO THE CHEST.}

BY J. DANIEL MOORE, M.D., F.L.S.,

DEPLTY CORONRR FOR THE COLNEY PALATINE OP LANCASTBR, AND HON. STRGEON TO THE LANCASTER INFIBMABY.

A VERY interesting case, illustrating the effect produced by discharging a pistol loaded with a small bullet only, fired close to the body, occurred in the person of W. B. Kendall, a man forty-three years of age, who committed suicide by shooting himself, and was found dead in his house in Lancaster on the 3rd of June, 1869.

When found, he was lying on his right side on the floor of the kitchen of his house.* There was a large pool of blood near him; and a pistol that had been recently discharged, having an exploded percussion cap on the nipple, was lying at his feet. The fingers of his right hand were blackened as if from the explosion of gunpowder. He was dressed in his usual clothing, was quite dead, and rigor mortis established.

I saw the body on the following morning, and found that there was a large hole in his coat, waistcoat, shirt, and under-shirt on the left side. The margins of the holes were scorched and ragged, and some of his clothes were saturated with blood. 'There was also an aperture in the wall of the chest sufficiently large to allow me to pass my band freely into the thoracic cavity. When the body had been stripped, this wound was found to be circular in shape, and nearly 3 in. in diameter; portions, about $2 \frac{1}{2}$ in. in length, of the fourth and fifth ribs, at about 3 in. from the sternum, on the left side, were in fragments, and carried into the chest. The margin of the Found was burnt, ragged, and slightly inverted. The inversion may, however, have been caused by the hands of several medical men having been introduced into the wound. On opening the chest, the heart was found to be intact, and situated nearer to the right side than its normal position. The left lung was completely shattered; and in its substance were several fragments of bone from the broken ribs, and pieces of cloth from his apparel. There was no aperture of exit, and for some time I failed to detect any shot or ball; but, on continuing my examination, I discovered a small leaden bullet, measuring about three-eighths of an inch in diameter, and weighing a drachm and a half ( 72 to the $1 b$.), impacted in the substance of the left side of the fourth dorsal vertebra and head of the corresponding rib.

This case will be of importance to the medical jurist from showing the great extent of injury that may be inflicted with a pistol loaded with powder alone; I say powder alone, for a bullet so small as the one discovered could not inflict more than a comparatively small amount of the injury that the deceased received. I have no doubt but that the demolition of the chest-wall, covered with several thicknesses of clothing, to the extent of a circle nearly nine inches in circumference, the fragmentation of the ribs, and shattering of the lung, are entirely due to the muzzle of the pistol having been pressed closely to the chest; for had the injury been produced by the bullet alone, a small opening of little more than a quarter of an inch in diameter would have been the result; at the utmost one rib only would have been fractured. From the fact, however, that the centre of the opening corresponded with the intercostal space, I am inclined

* I am aware that the position in which I have stated the deceased to have been found differs from that given in evidence at the coroner's in. quest, but have reliable testimony from the person who mored the body as to its position before it was seen by the police authorities. 